\title{
Stunting and Associated Factors among Children Aged 6-59 Months in Lasta Woreda, North East Ethiopia, 2015: A Community Based Cross Sectional Study Design
}

\author{
Birhanu $\mathrm{A}^{1}$, Mekonen $\mathrm{S}^{1}$, Atenafu $\mathrm{A}^{1}$ and Abebaw \\ $\mathbf{D}^{2 *}$ \\ ${ }^{1}$ University of Gondar, Collage of Medicine and Health \\ Science, Institute of Public Health, Department of \\ Epidemiology and Biostatistics, Ethiopia \\ ${ }^{2}$ Department of Research and Training, Amanuel Mental \\ Specialized Hospital, Ethiopia \\ *Corresponding author: Dessie Abebaw, Department \\ of Research and Training, Amanuel Mental Specialized \\ Hospital, Ethiopia
}

Received: February 09, 2017; Accepted: March 03, 2017; Published: March 10, 2017

\begin{abstract}
Background: Stunting refers to low height-for-age as a result of chronic malnutrition. Globally, 165 million under five year's children were stunted annually, which was associated with 10.6 million deaths. Although stunting is increasingly being recognized as a widespread problem, precise data on the magnitude and associated factors of stunting was not available at the study area which was highly influenced by the local geo-cultural factor, custom and context.

Objective: The aim of this study was to assess prevalence and factors associated stunting among children aged 6-59 months in Lasta Woreda, North East Ethiopia.

Methods: A community based cross sectional study was conducted from March-April, 2015. A multistage sampling strategy with simple random sampling approach was used with total sample size units of 825. Data were collected Using validated questionnaire through interviewing parents or caregivers and Anthropometric measurement. EPI INFO version 7 software was used for data entry. For Analysis SPSS version 20 statistical software was used. Principal component Analysis was applied to compute wealth index. Z-Score of the children were calculated using SMART software (ENA2011). To identify the association and significant predictors, binary logistic regression was employed.

Results: A total of 759 study participants were included in the study giving response rate of $92 \%$. The overall prevalence stunting was $49.7 \%(95 \% \mathrm{Cl}$ : 46.1-53.3). Among this 57.7\%; (95\% Cl: 50.9-60.4) were male and $42.3 \%$ (95\% Cl: 36.8-47.6) were female. The proportion of moderate and sever stunting among study population was $31.7 \%$ and $18.0 \%$ respectively. Being male AOR= 1.90; (95\% Cl; 1.29-2.82), increasing age (AOR = 8.38; (95\% Cl: 3.78-15.6)), large family size $(\mathrm{AOR}=1.78$; $(95 \% \mathrm{Cl} ; 1.19-2.65))$, poor wealth status (AOR = 2.64; $(95 \% \mathrm{Cl}$; 1.58-4.41)), illiterate mother (AOR = 4.02; (95\% Cl: 2.3-7.04)), leftover food (AOR=1.94; (95\% Cl: 1.30-2.90)), living in rural area $(A O R=2.08$; (95\% Cl: $1.10-4.19))$ and less frequency of feeding (AOR $=2.13 ;(95 \% \mathrm{Cl}: 1.18-$ 3.82)) were significantly associated with stunting.
\end{abstract}

Conclusion: This study shows that, the prevalence of stunting among children aged 6-59 months in Lasta Woreda is higher as compared to the national figures (MEDHS, 2014). Being male, increasing age, large family size, giving leftover food, poor wealth status, and illiterate parents were factors associated with stunting. Urgent, therapeutic and targeted supplementary feeding programs need to be considered for chronically malnourished children in Lasta Woreda to reduce stunting. Factors associated to stunting as identified with this study need to be considered for the intervention plan.

Keywords: Stunting; 6-59 months children; Lasta Woreda; Ethiopia

\section{Background}

Stunting refers to low height-for-age as a result of chronic malnutrition. Stunting in children under five is defined as a height for age less than Z-scores below minus two standard deviations (-2SD) of the World Health Organization (WHO) child growth standards median $[1,2]$. Stunting has negative consequence for a child's physical and mental development. Children who are stunted tend to achieve lower scores on intelligence and are more likely to become affected by infections $[3,4]$. Improved nutrition with adequate feeding and care develop the intellectual ability of the children [5].

Globally under nutrition, cause $45 \%$ of all deaths of children younger than five years, which is equivalent to 3.1 million deaths $[6,7]$. Worldwide out of four children, one is stunted and in developing countries one in three and specifically in Africa two out of five children's suffered with stunting [5,8].

In Ethiopia, more than 2 out of every 5 children stunted,
J Fam Med - Volume 4 Issue 3 - 2017

ISSN : 2380-0658 | www.austinpublishinggroup.com

Birhanu et al. (C) All rights are reserved
Citation: Birhanu A, Mekonen S, Atenafu A and Abebaw D. Stunting and Associated Factors among Children Aged 6-59 Months in Lasta Woreda, North East Ethiopia, 2015: A Community Based Cross Sectional Study Design. J Fam Med. 2017; 4(3): 1112. 
Table 1: Sampling Procedure.

\begin{tabular}{|c|l|c|}
\hline Outcome variables & \multicolumn{1}{c|}{ Assumption } & Final sample size \\
\hline Stunting & $\begin{array}{l}\text { 95\% confidence interval, , 5\% margin of error and 10\% none response, 2 design effect and considering 42.4\% } \\
\text { population proportion }\end{array}$ & $\mathbf{8 2 5}$ \\
\hline
\end{tabular}

educational achievement of these stunted children is 1.1 years later than non stunted children and $16 \%$ of all repetitions in primary school are associated with stunting [9].

In Ethiopia $40 \%$ of children under age five were stunted and $18 \%$ of children were severely stunted with regional variation such as in South Nation Nationality Peoples $44.3 \%$, Afar $49.2 \%$, Tigray 44.4\%, Amhara National Region State $42.4 \%$ children under five were stunted [10]. Stunting reduce a child's chance of survival, hindering optimal health and growth and associated with suboptimal brain development, which is likely to have long-lasting harmful consequences for cognitive ability, school performance and future earnings [11].

Stunting is affected by many factors such as: poverty, low parental education, lack of sanitation, low food intake, poor feeding practices, inadequate breastfeeding, repeated infections, family size and birth interval $[12,13]$. Comprehensive knowledge about the risk factors of stunting in local context is vital to reduce stunting rate, to develop prevention strategies and strengthen nutrition intervention programs.

Moreover, the stunting status of children is a manifestation of a host factors, including household access to food and the distribution of this food within the household, availability and utilization of health services and the care provided to the child [14]. Though there is progress from government to improve the nutritional status of the children, stunting among children is still very high according to Ethiopian Demographic Health survey figure (40\%) and hence, there is a limitation of information on associated factors of stunting. Therefore the purpose of this study was to assess prevalence and factors associated with stunting among children aged 6-59 months in Lasta Woreda, North East Ethiopia.

\section{Justification of the study}

Stunting is a well-established risk marker of poor child development, measure of linear growth and a condition reflecting the cumulative effect of chronic malnutrition [14].

Although stunting is increasingly being recognized as a widespread problem, to my knowledge precise data on the magnitude and associated factors of stunting was not available at the study area which was highly influenced by the local geo-cultural factor, custom and context. For this more comprehensive study was needed to asses prevalence and associated factors of stunting.

Therefore, this Study assessed the prevalence and associated factors of stunting among children aged 6 to 59 months in Lasta Woreda. The study will help and provide evidence for different stakeholders who are working on child nutrition, to plan appropriate and the most effective nutrition intervention in the study setting.

\section{Objective}

\section{General objective}

The aim of this study was to ass's prevalence and factors associated with stunting among children aged 6-59 months in Lasta Woreda,
North East Ethiopia, 2015.

\section{Specific objectives}

- To determine prevalence of stunting among children aged 6-59 months in Latsa Woredas, 2015.

- To identify factors associated with stunting among children aged 6-59 months, in Lasta Woreda, 2015.

\section{Methodology}

\section{Study design}

Community based cross sectional study was employed.

\section{Study area and period}

This study was conducted in Lasta Woreda which is found in North Wollo Zone, North East Ethiopia in Amhara national regional state. The district has 24 rural Kebeles with a total population of 115880.00 and 14925 of the child are aged 6-59 months of old and 26949 households, which are projected from 2007 Central Statistics Agency (CSA) census. There are 6 Cluster Health Centers and 24 health posts in Lasta Woreda and one Hospital in Lalibela Town. The data collection period was from March 22 -April 30/2015.

\section{Source population}

The source populations were all children aged 6-59 months who are living in Lasta Woreda.

\section{Study population}

The study populations were children aged 6-59 months in Lasta Woreda from selected kebeles.

\section{Inclusion and exclusion criteria}

Inclusion criteria: All children aged 6-59 months who were living in Lasta Woreda were included in this study.

\section{Sample size and Sampling procedure}

Sample size determination: Sample size was calculated using single population proportion formula, assuming A Z- value of 1.96 was used at $95 \%$ CI and $d$ of $5 \%$. Where ( $n=$ sample size, $p=$ prevalence, $d=$ margin of error, $Z=$ level of confidence $\left.(1.96)^{2}\right)$ and taking the prevalence (p) of stunting was $42.4 \%$ in ANRS among under five children [10].

$$
\begin{aligned}
& \mathbf{n}=\left(\mathbf{z}_{\boldsymbol{\alpha} / 2)^{2}}{ }^{2} \times \frac{\mathbf{p}(1-\mathbf{p})}{(\mathbf{d})^{2}}\right. \\
& \mathbf{n}=(1.96)^{2} \times \frac{\mathbf{0 . 4 2 4}(1-0.424)}{(0.05)^{2}} \\
& =375
\end{aligned}
$$

By using 2 design effect $375^{\star} 2=750$ and Adding 75 contingency for non response, therefore the final sample size used were $=825$ (Table 1).

To consider the second objective Sample size was calculated as following:

The larger sample 825 from the outcome variable was selected as a final sample size sampling procedures. 


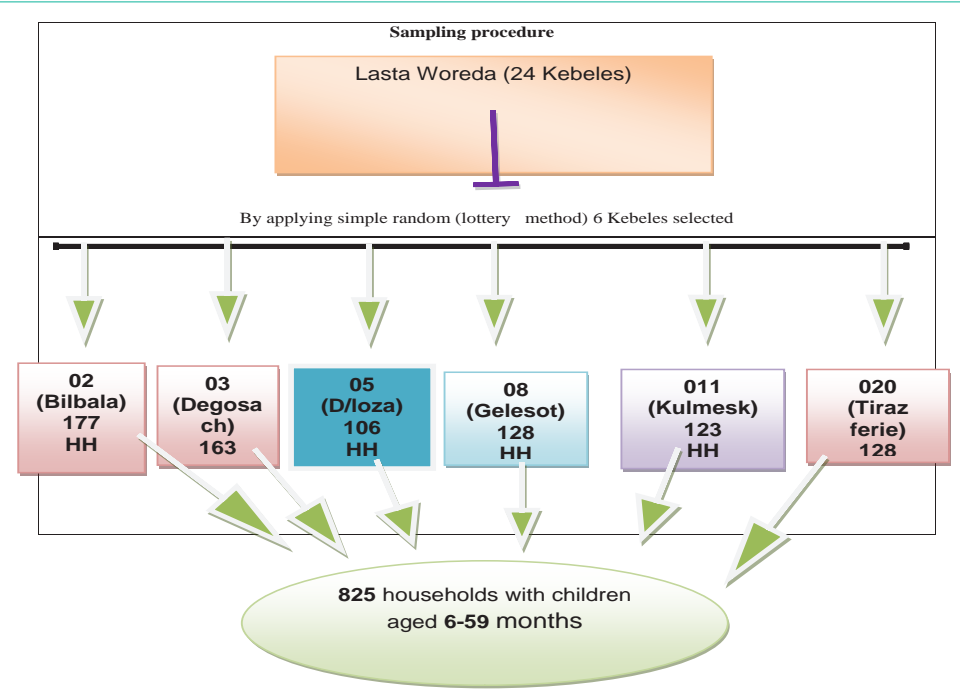

Figure 1: Sampling procedure.

In this study multi-stage sampling technique with simple random sampling approach was employed. From 24 kebeles of Lasta Woreda $25 \%$ of the kebele was selected by simple random lottery method (Figure 1). The sample size was allocated proportionally for each selected Kebeles by using proportional allocation formula.

$$
\mathrm{ni}=\frac{\mathrm{n}}{\mathrm{N}} \times \mathbf{N i}
$$

Where $\mathrm{n}=$ total sample size to be selected, $\mathrm{N}=$ Total population, $\mathrm{Ni}=$ total population of each kebele, $\mathrm{ni}=$ sample size from each kebele.

Simple random sampling (computer generating number) technique was applied to get the sampling unit from the available list and collect the data from each Kebeles the allocate numbers of sample size. For the case of more than one child of the targeted age from the household, lottery method was used to select one of the children.

\section{Operational definitions}

Stunting: A child was defined as Moderate and severe stunted; when height-for-age Z-score between $-2 \mathrm{SD}$ to $-3 \mathrm{SD}$ and $<-3 \mathrm{SD}$, respectively from the median of WHO reference population.

Under nutrition: children who were stunted considered as undernourished children.

\section{Data collection procedure}

Data were collected using validated questionnaire through interviewing parents/caregivers in the household. Anthropometric measurement was applied for the anthropometric data (height of the child). The questionnaire was first developed by English and then translated in to Amharic version to minimize information bias then back to English to assure its consistency. Eight nurse professional data collectors and 3 health officers for supervision were recruited. Appropriate training was provided for the data collectors and supervisor by Principal investigator. The Anthropometric measurement was done for all children aged 6-59 months in order to asses there stunting status. The anthropometric data was collected using the procedure predetermined by the WHO (2006) for taking anthropometric measurements. Before taking anthropometric data for children; first their age was determined in order to ensure the target population.

Height/length measurement: for body length of children age up to 23 months measurement was read to the nearest $0.1 \mathrm{~cm}$ by using a horizontal wooden length board with the infant in recumbent position. However, for height of children aged 24 months and above was measured using a vertical wooden height board with detachable sliding headpiece which was designed by UNICEF, by placing the child on the measuring board and child standing upright in the middle of board. The child's head, shoulders, buttocks, calf and heels touching the board.

\section{Data quality management}

To insure quality of data, two days training was given for data collectors and supervisors before data collection on how to approach study subjects, on how to use the questionnaire, demonstration how to measure length/height and about ethics during field work was properly addressed. Pre test was done in Similar Kebele which was not included in the main study by taking $5 \%$ (which was 40 individual) of the sample size. Necessary correction was done after the pre test and appropriate measure was taken on time for completeness before data entry. The collected data was checked out for completeness, accuracy and clarity by principal investigator and supervisors. Data clean up and cross-checking was done before analysis. Supervision was also done at the spot by principal investigator and supervisors.

\section{Data processing and analysis}

After coding, the data was entered to EPI INFO version 7. It was exported to SPSS version 20 for analysis and appropriate recoding was made. Frequencies, proportion, means and SDs were used to summarize descriptive statistics of the data and tables and graphs were also used for data presentation.

To define the outcome variable, anthropometric data were converted in to Z-Score using Emergency Nutrition Assessment (ENA) for SMART special software, 2012. Z-Score of the child was categorized based on the WHO cut point. Then stunting was defined and coded as $1=$ stunted, $0=$ normal. 
Table 2: Socio-economic and demographic characteristics of children and their parents, Lasta Woreda, North East Ethiopia, 2015, ( $N=734)$.

\begin{tabular}{|c|c|c|}
\hline Characteristic & Frequency & percent \\
\hline \multicolumn{3}{|l|}{ Age of Child in month } \\
\hline 6-11 months & 83 & 11.3 \\
\hline 12-23 Months & 224 & 30.5 \\
\hline 24-35 Months & 168 & 22.9 \\
\hline 36-47 Months & 125 & 17 \\
\hline 48-59 Months & 134 & 18.3 \\
\hline \multicolumn{3}{|l|}{ Sex of The child } \\
\hline Female & 323 & 44 \\
\hline Male & 411 & 56 \\
\hline \multicolumn{3}{|c|}{ Educational status of mother } \\
\hline cannot read and write & 523 & 71.3 \\
\hline can read and write & 131 & 17.8 \\
\hline primary education & 45 & 6.1 \\
\hline secondary education & 29 & 4 \\
\hline higher education & 6 & 0.8 \\
\hline \multicolumn{3}{|c|}{ Educational status of father } \\
\hline Cannot read and write & 481 & 65.5 \\
\hline can read and write & 181 & 24.7 \\
\hline primary education & 39 & 5.3 \\
\hline secondary education & 22 & 3 \\
\hline higher education & 11 & 1.5 \\
\hline \multicolumn{3}{|l|}{ Maternal occupation } \\
\hline House wife & 639 & 87.1 \\
\hline Student & 18 & 2.5 \\
\hline Merchant & 30 & 4.1 \\
\hline Other* & 47 & 6.3 \\
\hline \multicolumn{3}{|l|}{ Paternal occupation } \\
\hline Farmer & 661 & 90 \\
\hline Merchant & 35 & 5 \\
\hline Employee & 22 & 3 \\
\hline Other* & 16 & 2 \\
\hline \multicolumn{3}{|c|}{ Number of U5 Children per $\mathrm{HH}$} \\
\hline$<=2$ & 609 & 83 \\
\hline$>=3$ & 125 & 17 \\
\hline \multicolumn{3}{|l|}{ Family size } \\
\hline$<=4$ & 392 & 53.4 \\
\hline$>=5$ & 342 & 46.6 \\
\hline \multicolumn{3}{|l|}{ Heads Household } \\
\hline Mother & 181 & 24.7 \\
\hline Father & 522 & 71.1 \\
\hline grand mother & 17 & 2.3 \\
\hline grand father & 14 & 1.9 \\
\hline Decision maker on how to mon & & \\
\hline
\end{tabular}

\begin{tabular}{|c|c|c|}
\hline Husband & 412 & 56.1 \\
\hline Wife & 82 & 11.2 \\
\hline Both & 220 & 30 \\
\hline Other** & 20 & 2.7 \\
\hline Religion & & \\
\hline Orthodox Christian & 701 & 95.5 \\
\hline Muslim & 33 & 4.5 \\
\hline Wealth Index & & \\
\hline Poor & 263 & 35.8 \\
\hline Medium & 274 & 37.3 \\
\hline Rich & 197 & 26.9 \\
\hline
\end{tabular}

*= Employed, daily labor and ${ }^{* *}=$ grandmother, grand father.

Binary logistic regression was fitted for this study. Firstly, bi-variable logistic regression analysis was performed to screen determinants factor of stunting among children aged 6-59 months. Secondly, those predictor variables which were significantly associated with outcome variable (stunting) at 0.2 and less level of significance from the bi-variable logistic regression analysis were entered in to the multivariable logistic regression model; for controlling the possible effect of confounders.

Enter method was used for selection of significant predictors in the multivariable logistic regression analysis. Coefficients were reported as crude and adjusted OR relative to the reference category. The variables which have a statistical significance association were identified on the basis of $p$-values $\leq 0.05$ and AOR with $95 \%$ confidence intervals. The model fitness for multivariable logistic regression was checked by with Hosmer and Lemeshow test for goodness-of-fit and maximum likelihood ratio or Chi-square difference test.

\section{Ethical consideration}

Ethical clearance was obtained from Institutional Review Board of Institute of Public Health, College of Medicine and Health Sciences, University of Gondar. Permission letter was obtained from Lasta Woreda Administrative Health Office to the respective Kebeles health centers, cluster health center and health posts. The purpose and importance of the study was explained for study participants and informed the right to withdraw at any time during the study period.

Participants were recruited after signing the written informed consent. No personal identification such as name was collected to maintain the privacy and confidentiality of participants. Identified cases of severely malnourished (14) during the study were referred to nearby Health Facility for treatment.

\section{Results}

\section{Socio-economic and demographic characteristics of households}

A total of 825 study participants were included in the study giving response rate of $759(92 \%)$. The majority participants were mother with mean age of 30 and $S D \pm 6.7$. Male children who had participated in this study were $411(56 \%)$ and $323(44 \%)$ were female (Table 2). The mean $( \pm \mathrm{SD})$ age of children have been participated in this study were 27.6 and 15.4 months, respectively. Households who had only one child aged 6-59 months and more than one child aged 6-59 months 
Table 3: Factors associated with stunting, Lasta Woreda, North East Ethiopia, 2015.

\begin{tabular}{|c|c|c|c|c|}
\hline \multirow{2}{*}{ Predictors } & \multicolumn{2}{|c|}{ Frequency } & \multirow[t]{2}{*}{ COR (95\% C.I.) } & \multirow[t]{2}{*}{ AOR (95\% C.I.) } \\
\hline & Stunted & Normal & & \\
\hline \multicolumn{5}{|l|}{ Sex of children } \\
\hline Female & 136 & 187 & 1 & \\
\hline Male & 229 & 182 & $1.73(1.28-2.32)$ & $1.90(1.29-2.82)^{\star *}$ \\
\hline \multicolumn{5}{|l|}{ Age of the children } \\
\hline 6-11 Months & 23 & 60 & 1 & 1 \\
\hline 12-23 Months & 107 & 117 & $2.38(1.38-4.12)^{\star *}$ & 3.38 $(1.69-6.76)^{\star *}$ \\
\hline 24-35 Months & 87 & 81 & $2.80(1.58-4.94)^{\star \star}$ & $6.41(3.02-13.60)^{\star *}$ \\
\hline 36-47 Months & 74 & 51 & $3.78(2.08-6.88)^{\star \star}$ & $8.38(3.78-15.6)^{\star \star}$ \\
\hline 48-59 Months & 74 & 60 & $3.21(1.78-5.79)^{\star \star}$ & $5.39(2.5-11.6)^{\star \star}$ \\
\hline \multicolumn{5}{|l|}{ Total family size } \\
\hline$<=$ four & 169 & 223 & 1 & \\
\hline >= five & 196 & 146 & $1.77(1.32-2 \cdot 375)^{\star \star}$ & $1.78(1.19-2.64)^{\star}$ \\
\hline \multicolumn{5}{|l|}{ Maternal Education } \\
\hline Illiterate & 334 & 189 & $10.26(6.74-15.63)^{\star \star}$ & $4.02(2.3-7.039)^{\star \star}$ \\
\hline Literate & 31 & 180 & 1 & \\
\hline \multicolumn{5}{|l|}{ Paternal Education } \\
\hline Illiterate & 326 & 155 & $11.54(7.8-17.1)^{\star \star}$ & $8.0(4.70-13.60)^{\star \star}$ \\
\hline Literate & 39 & 214 & 1 & 1 \\
\hline \multicolumn{5}{|l|}{ Left over feed to child } \\
\hline Give to child & 183 & 134 & $1.76(1.31-2.36)^{\star \star}$ & $1.944(1.30-2.90)^{\star \star}$ \\
\hline Didn't Given & 182 & 235 & 1 & \\
\hline Three times per day & 91 & 98 & $1.04(0.74-1.472)$ & $1.42(0.89-2.27)$ \\
\hline Four and above times & 200 & 225 & 1 & 1 \\
\hline \multicolumn{5}{|l|}{ Residence } \\
\hline Urban & 25 & 70 & 1 & 1 \\
\hline Rural & 340 & 299 & 3.18 $(1.96-5.16)^{\star \star}$ & $2.08(1.10-4.19)^{\star \star}$ \\
\hline \multicolumn{5}{|l|}{ Wealth index } \\
\hline Poor & 169 & 94 & $2.62(1.80-3.84)$ & $2.64(1.58-4.41)^{\star *}$ \\
\hline Medium & 116 & 158 & $1.07(0.74-1.56)$ & $0.68(0.42-1.1)$ \\
\hline Rich & 80 & 117 & 1 & 1 \\
\hline
\end{tabular}

Note: ${ }^{*}=$ p.v $\leq 0.05,{ }^{* *}=p . v \leq 0.003$.

NB: Enter method was used to select predictors. The model adequately fits the data at P-value 0.637 (Hosmer and Lemeshow Test; for goodness of fit).

were $486(66.2 \%)$ and $248(33.8 \%)$, respectively.

Educational status of participant shows that, Mothers who cannot read and write and can read and write (informal school) were 523(71.3\%) and 131(17.8\%), respectively. Mothers who attend primary, secondary and higher education were 45 (6.1\%), 29(4\%) and $6(0.8 \%)$, respectively.

Wealth status of the participant shows that, households who are poor, intermediate and rich were found to be 263(35.8\%), 274(37.3\%) and 197(26\%), respectively (Table 2).

\section{Prevalence of stunting/height-for-age}

Among Children 6-59 months; 365(49.7\%) (95\% CI; 46.1-53.3) were stunted. The prevalence were different between male and female, which were 229(31.2\%); (95\% CI: 27.8.-34.5) and 136(18.5\%); (95\%CI: $15.7-21.3)$, respectively. Mean $( \pm$ SD) of HAZ was $-2.16 \pm 1.56$ among all children. Prevalence of moderate and severe stunting were 233 (31.7\%) (95\% CI: 28.5-35.2) and 132 (18.0\%); (95\% CI: 15.420.9), respectively (Figure 2).

\section{Associated factors of stunting}

This study identified that; being male, increasing age of children, 


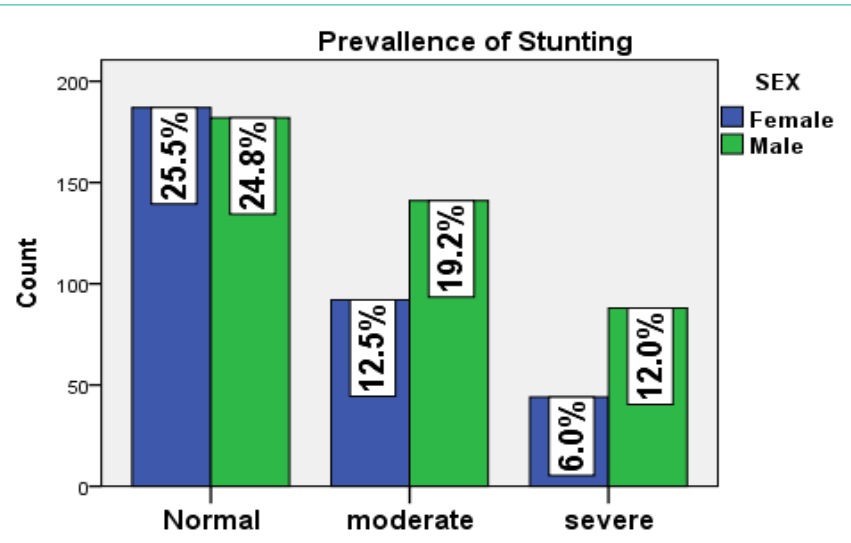

Figure 2: Prevalence of moderate and severe stunting by sex category among children aged 6-59 months in Lasta Woreda, North East Ethiopia, 2015.

large family size, Illiterate parents, rural residence, giving leftover food for child, less frequency of feeding and poor wealth index were statistically associated factors to stunting at $p$-value $\leq 0.05$ (Table 3 ). Dietary diversity score(food groups), Initiation of complementary feeding, pre-lacteal feeding, main source of income, birth order of the children, Methods of feeding, washing hand, water treatment, Head of Household, duration of breast feeding and duration of exclusively breast feeding were associated with stunting during Bi-variable Logistic regression analysis but not statistically associate during multivariable regression and controlled.

The odds of being stunted were about 8 times higher among children age group 36-47 as compared to children 6-11 months old $(\mathrm{AOR}=8.38$; (95\% CI: 3.78-15.6). The odds of being stunted were about 2 times higher among male children than girls $(\mathrm{AOR}=1.90$; (95\% CI; 1.29-2.82). The odds of being stunted were 1.78 times higher among children living in large family size $(\geq 5)$ households than those living small family size $(<5)$ (AOR=1.78; (95\% CI; 1.19-2.65).

The odds of being stunted were 4 times higher among children from illiterate mother than those who had educated mothers (AOR = 4.023; (95\% CI: 2.3-7.04). Likewise the odds of being stunted were 8 times higher among children from illiterate father than those who had educated father $(\mathrm{AOR}=8.0$ : (95\% CI: 4.70-13.60). The odds of being stunted were about 2 times higher among children who are feed less than 3 times per a day than those who were fed more frequently (AOR $=2.13$; (95\% CI: 1.18-3.82). The odds of being stunted were 2 times higher among children living in rural area than those living in urban areas $(\mathrm{AOR}=2.08$; $(95 \% \mathrm{CI}: 1.10-4.19)$. The odds of being stunted were about 2 times higher among children who were given leftover food than those who were fed with the other member of the family (AOR=1.94; (95\% CI: 1.30-2.90). The odds of being stunted were 2.6 times higher among children living in poor wealth status households than those living in higher wealth status households $(\mathrm{AOR}=2.64$; (95\% CI; 1.58-4.41).

\section{Discussion}

This study shows that about half of the children under the study were stunted. Of this $57.7 \%$ were male and $42.3 \%$ were female. The proportion of moderate and sever stunting among study population were $31.7 \%$ and $18.0 \%$ respectively. Being male, increasing age, large family size, poor wealth status, illiterate mother, place of residence, illiterate father and giving leftover food were risk factors associated with stunting.

This finding is very high compared with the WHO Cut off point set for stunting ( $\geq 40 \%$ ) [15]. This finding is also higher as compared to the national (40\%) and the Amhara region (42.4\%) prevalence [10]. Similarly, studies done in Kenya (44.9\%) [16], Uganda (41.6\%), [17], Malaysia (41.1\%) [18] and Bangladesh (41\%) [19] showed low prevalence of stunting. This study is in line with similar studies done in Dollo Ado District of Somali region (47.7\%) [20], Afar (49.2\%) [10] and lower than the finding In Tigray region (56.6\%) [13]. The high prevalence observed in this study, might be due to the area is prone to drought and low annual production in the community. The disparity might be due to socio-economic, topographic, cultural similarity and deference, national difference and nutritional and health backgrounds. Even though Ethiopia GTP was target for 2014/15 to reduce stunting below $37 \%$ [21], still the target is not meet needs more attention and effort to achieve the target.

In this study the risk of stunting was increased as age increased. Children age groups 36-47 months and 24-35 months were strongly associated with stunting. This finding is in line with other studies done in Ethiopia; Oromia [12], Amhara [22] regions, Bangladesh [19] and inversely related with studies done in Somali region Ethiopia[20]. The reason might be insufficient supplementary feeding and care for older children to maintain adequate nutrition for growth. But, there is a tendency for the odds ratio to decrease as age increase, example, the odds ratio of being stunted for children 47-59 months were 5.4. The reason might be children gradually adopt supplementary foods after four years. This discrepancy might be due to socio-cultural and feeding variation between Somali Region and the study setting.

This study identified that family size was an important factor for stunting. Children living in large family size households were more likely to be stunted than those living small family size. This is in-line with studies in Ethiopia; Fogera District [23], Gurage Zone [24], SubSaharan Africa [25] and Asia [26]; This might be due to shortage of food, food competition with family and lack of care, because as family size increase they might be got shortage of food in the households and resource depletion which exposed to poverty. Other possible explanation might be because of high fertility per households which leads to high number of family and low socio economic status.

Maternal and paternal educational status is one of the most determinants of chronically malnutrition [7,27]. In this finding, maternal and paternal education status were strongly associated with stunting. The odds of being stunted for children among illiterate mother were 4 times higher than those who had educated mother. Likewise the odds of being stunting among children illiterate father were 8 times higher stunted as compared to those children who had educated father. This study is in-line with similar studies in Ethiopia $[10,12,13,23]$, in Africa $[17,28,29]$ and Asia $[26,30,31]$ countries. This might be due to Illiterate mothers and fathers were less aware of their children nutritional consequence than educated parents. Illiterate parents may less likely to introduce new feeding practice, which helps to improve the nutritional status of their children. 
Giving leftover food for children is the predominant traditional harm full practice according to WHO criteria [32]. In this finding, children who were given leftover food were more likely to be stunted than those who were fed with the other member of the family (were not given leftover food). This study is in-line with studies done in Ethiopia $[13,22,27]$. It might be because of, the leftover food might not be adequate, may be contaminated, quality less probably without wotte; which leads the children for frequent sickness and then finally become stunted. Beside this it might be because of low socioeconomic status of the households and low knowledge on the risk and conscience of giving leftover food for the children.

This study found that, the odds ratio of being stunted among children who was feed less than three times per a day were higher than those children who were fed four and above times per a day. This is in line with studies in Ethiopia West Gojam Zone [33] and in Asia $[30,31]$. The reason may be due to socio-economic status and feeding habit of the community. It might be due to the reason, in the study setting the frequency of feeding might be limited, feeding only launch and dinner may consider being sufficient. In addition to that, interruption of the eating habit or having irregular eating interval.

Household's wealth status were prominent factor for stunting. Children living in poor wealth status households were more likely to be stunted than those living in higher wealth status households. This is in line with similar studies in Ethiopia [10,22], Sub- Saharan Africa [25], Ghana [34] and In Asia [19]. This might be due to in adequate diet which might be caused by household food insecurity. Households with poor wealth index status might not be able to afford for the possible requirement to the child than households with rich wealth index. In addition to this it might be because of short raining season and short production season for low wealth index in the community. The lower wealth status from the family might increase the chance of children in the family sick and eventually become stunted.

Sex of the children is important demographic variable. Male children were more likely to be stunted than girls. This study is consistent with the other similar study in Ethiopia; Amhara and Tigray regions $[13,35]$ and Inconsistence with study in Oromia Region [12]. This discrepancy might be due to cultural and Environmental similarity and deference. The cause of this discrepancy in sex is not well established in the literature, but it might be due to boy were more exposed or influenced by environmental circumstance than girls.

In this study, place of residence had a significant association with stunting. Children living in rural areas were more likely to be stunted than those living in urban areas. It is in-line with studies in Ethiopia $[6,10]$ and Vietnam [26]. This might be due to lack of proper feeding and caring practice and knowledge about proper child feeding in the rural setting. And also children in rural place are more exposed to environmental circumstance.

\section{Limitations of the Study}

Some variables that need good memory were vulnerable for recall bias though it was tried to minimize.

Community and health facility characteristics were not included in this study.

\section{Conclusion and Recommendation}

\section{Conclusions}

This study shows that, the prevalence of stunting among children aged 6-59 months in Lasta Woreda is higher as compared to the regional and national figure. Half of the children were affected by stunting. Stunting continued to be a major challenge among children in the study setting.

Being male, less frequency of feeding, poor wealth status, increasing age of children, large family size, Illiterate parents, rural residence and giving leftover food for child were found to be significantly associated with stunting at $\mathrm{p}$-value $\leq 0.05$.

\section{Recommendations}

\section{For the community:}

- $\quad$ Avoid child sex preference between male and female during feeding and caring.

- Considering child age and their food requirement while feeding the child is recommended

- $\quad$ Giving leftover food, pre-lacteal feeding, late and early initiation of complimentary feeding need to be tackled.

- Frequency of feeding pattern to the child need to be increased

\section{For the health sector:}

- Education need to be given for the community for appropriate feeding practice and child health care.

- The ongoing therapeutic and targeted supplementary feeding programs need to be strengthened and considered chronically malnourished children.

- Health extension workers (HEWs) should strengthen giving nutrition education to create awareness about better feeding behavior among the community.

- $\quad$ Family planning program should be encouraged, in order to minimize family size.

- Nutrition surveillance needs to be done continuously (to screen chronically malnourished children)

\section{For agricultural sector:}

- Need to enhance the irrigations and farming mechanism in order to increase the households' asset.

\section{For Policy makers:}

- $\quad$ Awareness programs regarding affordable and nutritious foods need to be introduce by the government through community participation and involvement other sectors.

\section{For Researchers:}

- $\quad$ Further comprehensive study with advanced analysis of methodology is needed by including community and health facility characteristics. 


\section{Authors' Contributions}

The principal investigator designed the study, collect, entered and analysis the data. The investigator writes the final report and manuscript. All the authors revised and approved the final thesis report and manuscript. All authors read and approved the final manuscript.

\section{Acknowledgement}

I would like to express my heartfelt gratitude to my father Jesus who helped me to accomplish this thing successfully. Also my advisors Dr. Solomon Mekonen and Mrs. Azeb Atenafu Mr. Dessie Abebaw and who have been giving me a great help to the completion of this research thesis starting from commenting the draft of my proposal and thesis and giving very important suggestions. I would also like to extend my appreciation to those who have helped me a lot in giving additional advice and to those who participated in this study like supervisors and data collector and participants.

\section{References}

1. WHO. WHO child growth standards and the identification of severe acute malnutrition in infants and children. 2009.

2. WHO. Fact sheet on the implementation of 2006 WHO Child Growth Standards for emergency nutrition programmes for children aged6-59 months. 2009.

3. UNICEF, WHO, World Bank. United Nations Children's Fund, World Health Organization. The World Bank. UNICEFWHO-World Bank Joint Child Malnutrition Estimates. 2012

4. WHO. Child growth standards and the identification of sever acute malnutrition in infant and children. A joint statment by WHO and UN. 2009.

5. Addis Continental Institute of Public Health. Community-Based SubComponent Of Ethiopian National Nutrition Program. 2009.

6. LANCET. Executive Summary of the Lancet Maternal and Child Nutrition Series. 2013

7. Zulfi qar A Bhutta, Jai K Das, Arjumand Rizvi, Michelle F Gaffey, Neff Walker Susan Horton, et al. Evidence-based interventions for improvement of maternal and child nutrition: what can be done and at what cost? The Lancet Nutrition Interventions Review Group, and the Maternal and Child Nutrition Study Group. 2013

8. Central Statistical Authority. Demographic and Health Survey 2011; Addis Ababa, Ethiopia and ICF International Calverton, Maryland. USA. March, 2012. 2012.

9. Federal Ministry of Health (FMoH), Ethiopian Health and Nutrtion Research Institute (EHNRI). The Social and Economic Impact of Child Undernutrition in Ethiopia Summary Report. 2012.

10. CSA. Ethiopia Mini Demographic and Health Survey. 2014

11. United Nations Children's Fund (UNICEF). IMPROVING CHILD NUTRITION The achievable imperative for global progress. 2013.

12. Mengistu K, Alemu K, Destaw B. Prevalence of Malnutrition and Associated Factors Among Children Aged 6-59 Months at Hidabu Abote District, North Shewa, Oromia Regional State. Nutritional Disorders \& Therapy. 2012.

13. Alemayehu M, Tinsae F, Haileslassie K, Seid O, G/egziabher G, Yebyo H. Nutritional status and associated factors among under-five children, Tigray, Northern Ethiopia. International Journal of Nutrition and Food Sciences. 2013; 3.

14. World Health Organization. Global Nutrition Targets 2025 Stunting Policy Brief, Geneva. 2014
15. WHO. Global Database on Child Growth and Malnutrition.

16. Magaju P. Factors Associated With The Prevalence Of Under-Nutrition In Pre-School Children In Matisi Peri-Urban Location, Trans-Nzoia District, Kenya. Journal of Biology, Agriculture and Healthcare. 2013, 3.

17. Turyashemererwa FM, Kikafunda JK, and E Agaba. Prevalence of Early Childhood Malnutrition And Influencing Factors In Peri Urban Areas Of Kabarole District, Western Uganda. African Journal of Food Agriculture Nutrition and Development. 2009; 9: 975-989.

18. Tumwine Jk, Kikafunda, M. Owor. Socio-Economic Risk Factors for Severe Protein Energy Malnutrition Among Children In Mulago Hospital, Kampala. 2007; 77: 471-475

19. Jahangir Alom M, Abdul Quddus. Mai. Nutritional Status of Under-Five Children In Bangladesh: A Multilevel Analysis. Journal of Biosocial Science. 2012; 44: 525-535.

20. Demissie S, Worku A. Magnitude and factors associated with malnutrition in children 6-59 months of age in pastoral community of Dollo Ado district Somali region, Ethiopia Science Journal of Public Health. 2013; 1: 175-183.

21. FDRE. Growth and Transformation plan 2010/2011-2014/2015. Policiy matrix. 2010; 2 .

22. Yalew BM. Prevalence of Malnutrition and Associated Factors among Children Age 6-59 Months at Lalibela Town Administration, North WolloZone, Anrs, Northern Ethiopia. Nutritional Disorders \& Therapy. 2012; 4.

23. Mekonnen $\mathrm{H}$. Malnutrition and its Correlates among Rural Primary Schoo Children of Fogera District, Northwest Ethiopia. Nutritional Disorders \& Therapy. 2013.

24. Fikadu. T, Assegid. S, Dube L. Factors associated with stunting among children of age 24 to 59 months in Meskan district, Gurage Zone, South Ethiopia: a case-control study. BMC Public Health. 2014.

25. Kravdal $\varnothing$, Kodzi I. Children's stunting in sub-Saharan Africa: Is there an externality effect of high fertility? Demographic Research. 2011; 25: 18

26. Hien $\mathrm{Nn}$, Hoa nn. Nutrition status and determinants of malnutrition in children under three years of age in Nghean, Vietnam. Pakistan Journal of nutrition. 2009; 8.

27. Alive \& Thrive. IYCF Practices, Beliefs, and Influences in SNNPR Region, Ethiopia. 2010

28. Lorretta Ntoimo, Clifford Odimegwu. Health effects of single motherhood on children in sub-Saharan Africa: a cross-sectional study. BMC Public Health. 2014; 14: 1145

29. Nikoi EGA. Child Nutritional Well-being in Ghana: An Analysis of Associated Individual, Household, and Contextual Health Indicators and Socioeconomic and Biophysical Environmental Variables. 2011.

30. Srivastava A. Does the community SES modify the household-level effects on child malnutrition in the Empowered Action Group (EAG) states of India? 2013.

31. Vandana Sati, Saroj Dahiya. Nutritional Assessment of Rural School-Going Children (7-9 Years) of Hisar District, Haryana. Open Access Scientific Reports. 2012; 1.

32. WHO. Infant and Young Child Feeding, A tool for assessing national practices, policies and programmes. 2003.

33. Beka T, Wambui K, Zewditu G, Girum T. Magnitude and determinants of stunting in children underfive years of age in food surplus region of Ethiopia: The case of West Gojam Zone. Ethiop J Health Development. 2009; 23: 98106.

34. Hong R. Effect of economic inequality on chronic childhood undernutrition in Ghana. 2006; 10: 371-378.

35. Teshome B, Kogi-Makau W, Getahun Z, Taye G. Magnitude and determinants of stunting in children underfive years of age in food surplus region of Ethiopia: The case of West Gojam Zone. Ethiop J Health Dev. 2009; 23: 98-106. 